minology up-to-date and to improve subject collocation, as well as in increasing use of subject faceting and notational synthesis. However, Miksa finds that the DDC is still based on three assumptions that, if unexamined, could have a negative effect on its future and on the future of $l i$ brary classification in general. These assumptions are: "knowledge categories are by nature hierarchical and logical; one best classification system is achievable; and document retrieval is the main purpose of library classification" (p. 82).

Only in his conclusion does Miksa consider the "post-modern library," by which he means both an evolving concept of the library as a personal space, made possible by electronic information and modern telecommunications, and the library as a product of the post-modern age, in which knowledge and truth are no longer absolute and everything is relative. The best hope for the survival and continued relevance of the DDC in this age lies in a thorough reconception of the system, including variable levels of specification and alternative arrangements for collocating information.

This slim book will interest readers who are curious about the history of libraries and the classification of knowledge. Its relevance is not limited to libraries using the DDC or to classifiers. It is very well organized, though it may provide a little too much detail on the history of the various editions of the DDC and not enough insight into possible future developments. A nine-page reference list is included. -John Hostage (hostage@ law.harvard. edu), Authorities Librarian, Harvard Law School Library, Cambridge, Mass.

Communicating Research. A. J. Meadows. San Diego, Calif.: Academic Press, 1998. 266p. \$59.95. (ISBN 0-12-487415-0). LC97-23432.

In Communicating Research, A. J. Meadows begins by stating that " $\mathrm{Commu}$ nication lies at the heart of research . . . for research cannot properly claim that name until it has been scrutinized and accepted by colleagues" (p. ix). This is obvious, but perhaps too easily taken for granted. Throughout this book, Meadows reiterates that understanding results from communication-from the interaction between the researcher and the receiver of research information. Research communication continues to evolve, most recently with the introduction of electronic networks-Meadows summarizes his main theme as "change and diversity" (p. 239). In his view, changes in the research communication process are not driven solely by technology, but also by the needs of the research community. $\mathrm{He}$ recognizes the effects of the technology, but considers it in its proper place as a tool of the researcher.

This book provides a good overview of the history and evolution of research communication, with a concise timeline that proceeds from Aristotle's symposia to the invention of printing, the development of postal systems, and the rise of the modern research journal as learned societies found meetings, personal correspondence, and books inadequate to keep a growing audience abreast of expanding research.

The emphasis in Communicating Research is on academic research, though private industry and government-funded research are included as a basis for comparison. Meadows focuses mainly on research in the natural sciences and includes humanities and social sciences research when he touches on the evolution of these distinct fields and the difficulty in defining the boundaries between them. A general characterization of the differences between the humanities and social sciences versus the natural sciences is that in the former, the book is more widely used as a tool of communication, while the journal article is most common in the latter. In addition, the emphasis in the natural sciences is almost always on the most current research, while older knowledge is read and cited more often in the humanities and social sciences. The structure of the journal article contributes to the efficiency of the communication process by providing the expected title, author, date of receipt (essential for establishing "first" discoveries, especially in the natural sciences), abstract, body (usually introduction, methodology, results, conclusion), and list of references. Books also have a typical layout, with an 
index to assist researchers in locating and absorbing information quickly.

The "professionalization" (p. 24) of research began in German universities, was well-established by the second half of the nineteenth century, and then spread to the rest of academia and eventually to industry and government. The size and education level of the research community began to grow, along with the amount of information it generated. Meadows makes the interesting point that the feeling of being overloaded with information actually has been common for a long time. To cope with the expansion of knowledge, universities were organized into departments and new disciplines were created through specialization or fusion.

The research community is subject to a set of social norms that are reflected in the communication process. When these norms are followed, they are invisible, but when they are not, plagiarism and the forging of research data may result. The community typically experiences periods of "normal science" interspersed with periods of "revolution," all documented through the recognized communication channels that record the cumulative knowledge of a discipline. Meadows discusses various aspects of research, including who performs research and why, the lower visibility of women researchers and those from developing countries, the effect of age on the researcher's output, the involvement of multiple authors in writing results, citation studies, and the roles of editors, referees, the mass media, and even amateur researchers. He highlights current trends, such as the increasing emphasis upon general, theoretical research as opposed to specific, empirical research (though this varies by discipline) and the increase in collaborative and interdisciplinary efforts.

The effects of technology on research communication are stressed throughout this book. Meadows points out that technological manipulation of bibliographic data helps researchers locate information. At first, only bibliographic citations were searchable by computer, then abstracts, and now full-text. He credits information technology with opening up new research opportunities and regular communication outside the research hierarchy, making the research process more democratic and open. Electronic networking allows wide dissemination of research in progress. On the other hand, these newer, more flexible channels bring a number of challenges: lines are blurred between formal and informal exchanges (when is something "pre-" and when is it a "print"?), questionable material can go undetected by the novice reader, data tampering can occur, and "electrocopying" can jeopardize copyright protection. There are citation difficulties, uncertainties regarding long-term archiving, and a continuing reluctance to accept electronic publishing within the academic community. Meadows endorses an ideal scenario in which print and electronic publication are parallel.

Though it is not the major focus of this work, Meadows recognizes the role of publishers and libraries in the research process. Publishers work with authors to assure that information is suitable for publication, that it is produced in an appropriate, legible format, and that it is well-disseminated. Libraries are the primary purchasers of scholarly publications; their selection decisions affect the actions of both publishers and readers, and these decisions are in tum often driven by the immediate needs of the institution's own researchers. The library's role is to archive the records of research and to make them available, a role that brings with it dilemmas regarding the financial inability to keep pace with publishing and the rising cost of physical storage. Both libraries and publishers face new challenges with electronic publishing, though Meadows believes that libraries have the most difficult task-storing and providing access to both the old and the new.

Electronic journals gained popularity first in the humanities and social sciences-articles are composed mainly of text, and publishing space was needed that was unavailable in print. The natural sciences are catching up now that technology can support the graphics required for publications in this field. Researchers at present recognize that a mix of print 
and electronic documents is the reality of the mid-1990s, but Meadows advocates more retrospective conversion to electronic format in order to expedite researchers' work. Paradoxically, information technology has made the researcher's task more difficult by increasing the amount of information, while at the same time making it more convenient for each researcher to access that information from a personal workstation. Meadows cautions that these electronic channels may further divide the information-rich from the information-poor, based upon the degree of access to information technology.

Many of the author's points are illustrated by tables with data on everything from "A Comparison of the Number of Articles Devoted to Astronomy/Space and Medicine at Two Epochs" (p. 73) to "The Existence of Bias in Refereeing Judgments" (p. 190). The concepts that Meadows presents are so interconnected and so often repeated that $I$ found myself pondering a better organization of this work while I read it. Yet in the end, I realized that this is the point: the communication of research is a complex, chaotic process that is constantly changing. The choice of the term "Postscript" for what I first considered a conclusion or summary seemed odd, but it became clear from the closing sentence that the author's clever play on the word "post-script" (p. 242) was intentional. Meadows correctly observes the myriad questions raised by the electronic channels of communication now available to researchers, although he unfortunately does not seem to have any greater insight than the rest of us into how it will all turn out.-Ellen McGrath (emcgrath@acsubuffalo.edu), Head of Cataloging, Charles B. Sears Law Library, State University of New York at Buffalo

\section{Budgeting for Information Access:} Managing the Resource Budget for Absolute Access. Eds. Murray S. Martin and Milton T. Wolf. Chicago: American Library Association, 1998. 174p. $\$ 30$ (ISBN 0-8389-0691-5). LC98-10964.

In Budgeting for Information Access,
Martin and Wolf define access very broadly as "finding, looking at, or using any printed or electronic information" ( $p$. 20). All types and formats of accessible collection-related materials, from print to electronic media, are discussed and examined in a series of short chapters. These include materials that are directly retrievable on-site in traditional and electronic formats and those received through interlibrary loan or document delivery services. Both editors are associated with Technicalities, a library journal and forum that represents the practitioner's point of view. Martin, who died in April 1998, was the author of the "Money Matters" column in Technicalities and many articles and books on budgets and library collections. Milton T. Wolf is the founding editor of Technicalities and is currently vice president for collection programs at the Center for Research Libraries.

Most of the chapters in Budgeting for Information Access contain practical information about collection-related concepts such as preservation, pricing, collection organization and maintenance, and budget implications. The "Notes" section in each chapter and the selective bibliography at the end of the book contain current and relevant source material, although the mention of some of these publications and studies is repeated too often throughout the text, as are material and charts from several of Martin's previous works.

The strength of this book lies in its discussion of budgeting and of the wide range of information alternatives available to libraries in the current marketplace. These alternatives include other collection-related areas-beyond print and electronic access-such as document delivery, interlibrary loan, resource sharing, and consortial and contractual relationships. This is important reading for acquisitions librarians whose functions overlap increasingly with areas outside their traditional domain, i.e., borrowing, leasing, and procurement for individuals, rather than purchasing materials to be cataloged and processed for the library collection. The thoughtful sections on developing a resource budget and on budget 